\title{
VIOLÊNCIA EM CRIANÇAS E ADOLESCENTES NO ESTADO DA BAHIA
}

\section{ARTIGO ORIGINAL}

POMPONET, Valesca Silva ${ }^{1}$

CASTRO, Isabele Sena de ${ }^{2}$

BATISTA, Luzinete Lopes ${ }^{3}$

OLIVEIRA, Maria Josenice Cruz ${ }^{4}$

BARBOSA, Terezinha Maria Santos ${ }^{5}$

SILVA, Mona Lisa Cordeiro Asselta da ${ }^{6}$

POMPONET, Valesca Silva. Et al. Violência em crianças e adolescentes no Estado da Bahia. Revista Científica Multidisciplinar Núcleo do Conhecimento. Ano 05, Ed. 06, Vol. 13, pp. 30-41. Junho de 2020. ISSN: 2448-0959, Link de acesso: https://www.nucleodoconhecimento.com.br/lei/criancas-e-adolescentes

\footnotetext{
${ }^{1}$ Graduanda em Direito.

2 Graduanda em Direito.

${ }^{3}$ Graduanda em Direito.

${ }^{4}$ Graduanda em Direito.

${ }^{5}$ Graduanda em Direito.

${ }^{6}$ Graduação em Odontologia. Especialização em Odontologia Legal. Mestrado em Saúde Coletiva. Doutorado em andamento em Programa de Pós- Graduação em Saúde Coletiva.
} 


\section{RESUMO}

Este trabalho busca investigar a violência caracterizada pelo uso da força e autoridade contra si ou outrem, podendo causar ferimentos leves, graves e danos psicológicos, principalmente em crianças e adolescentes. Diante disso, o artigo tem como objetivo principal explanar a problemática acerca do abuso sexual e maus tratos acometidos na infância e adolescência, traçando o perfil das vítimas de violência na Bahia no ano de 2016. Como metodologia, fez-se necessário o uso do estudo epidemiológico, no qual se usou dados do DATASUS, ano de 2016, tendo como base apenas o estado da Bahia. Objetivo: o intuito do estudo é explanar a problemática: abuso sexual e maus tratos na infância e adolescência. Traçar o perfil de crianças e adolescentes vítimas de violência na Bahia em 2016. Metodologia: estudo epidemiológico, no qual foram usados dados do DATASUS, ano de 2016 tendo como base o estado da Bahia.

Palavras-chave: Maus-tratos infantil, abuso sexual na infância, causas externas, agressão.

\section{INTRODUÇÃO}

A Organização Mundial da Saúde (OMS, 2002) define a violência como o uso da força e autoridade contra si ou outrem, podendo causar ferimentos leves, graves ou danos psicológicos. $O$ abuso e a negligência infantil se dão pela realização do ato em menores de 18 anos; o Artigo 136 do Código Penal, em seu decreto de lei 2848/40, vê como infração a exposição pelo responsável legal ao perigo da vida ou saúde do menor.

Em 1990 entrou em vigor no Brasil o Estatuto da Criança e do Adolescente (ECA), que prevê o amparo em lei e ordenamento jurídico para proteção deste grupo, independente de seus fatores biológicos ou sociais, condenando toda e qualquer ação que venha a deteriorar, agredir, explorar e pôr um fim ao período lúdico da infância, causando danos ao crescimento, seja ele físico ou psicológico. 
Crianças e adolescentes vêm sendo agredidas em seus ambientes de convivência, onde os agressores não são denunciados. Há 50 anos essa temática veio polemizar, pois, as consequências das agressões cresceram gradativamente, uma vez que a violência precoce e prolongada gera mais danos na saúde mental e física da vítima, ocasionando dificuldade na vida adulta.

No cenário baiano, o levantamento da ouvidoria do Ministério dos Direitos Humanos (2017), 58\% das ligações recebidas estão relacionadas a crianças e adolescentes e equiparam a situação estadual a nacional, mesmo que nem todos os casos sejam devidamente denunciados e formalizados. Dependendo do grau de proximidade do agressor, a família pode optar por ocultar o ocorrido e resolver de maneira informal, já a criança pode se sentir impotente e calar sua voz, guardando assim o ato e suas feridas, que quando físicas, dependendo do local, podem ser encobertas.

Em uma matéria escrita para o site Correio, a repórter Julia Vigné (2019) destaca que é dever dos familiares observar os sinais que as vítimas apresentam, como mudanças de comportamento, lesões, machucados, hematomas, medo de adultos ou de uma pessoa especifica, doenças sexualmente transmissíveis e tudo o que não for habitual. Após a descoberta da agressão ou violência, o menor pode ser direcionado para um profissional que o auxilie na superação do trauma e diminuição das sequelas.

Em julho de 2010, em comemoração aos 20 anos do Estatuto da Criança e do Adolescente, fora assinado um decreto lei que instituía o ensino sem uso da força e castigos, marcando um avanço no âmbito do aprendizado. Em consonância com o decreto, há um movimento chamado "Não Bata, eduque", composto por pessoas físicas e jurídicas, levam-se as crianças em um sentido contrário a banalização da violência, algumas instituições baianas são filiadas à rede. Além da agressão física e moral, a violência sexual também é grande causadora do fim da infância, de acordo com uma matéria escrita por Júlia Vigné (2019) e publicada no jornal diário O Correio, seis crianças ou adolescentes sofrem abusos sexuais por dia na Bahia, dados retirados da plataforma do Ministério dos Direitos Humanos. 
A ONG Childhood Brasil, criada em 1999, é uma extensão da World Childhood Foundation, uma instituição realiza projetos para garantir a proteção das crianças e adolescentes. Atuam por meio de parcerias com instituições públicas e privadas, a fim de instituir, auxiliar e prestar informações no combate aos abusos e violências sexuais infantis. A organização não fornece atendimento direto as vítimas e familiares, mas buscam proteger e garantir os direitos dos que necessitam, além de expandi-los socialmente para que interajam com o mundo.

Em uma entrevista prestada a ONG retromencionada a promotora Laila Shukair diz que se o mundo entende o filho do próximo como o seu próprio, logo poder-se-ia garantir uma criança feliz, o que leva a reflexão de que não se deve tratar o outro como um estranho por conta do vínculo curto, mas estender a ele um nível de empatia que o acolherá e o fará se sentir protegido, assim como seria feito com os descendentes.

Há poucos materiais didáticos que trabalhem a violência sexual em crianças e adolescentes, mas em 2014 a pedagoga e escritora Caroline Arcari lançou um livro chamado "Pipo e Fifi". A história inicia mostrando ao leitor as partes do corpo dos meninos e meninas, lembrando que alguns toques as crianças podem ou não gostar, posteriormente mostrando quais ações as crianças devem ficar atentas. A leitura é indicada para crianças maiores de 3 anos de idade e é aconselhado que seja lido com um responsável ao lado.

Ainda na literatura, O livro "Não me toca, seu boboca", da autora Andrea Taubman, traz a história de Ritoca e seus amigos que acabam por conhecer um novo morador da vizinhança, inicialmente muito gentil com as crianças, chama-os para ir até a sua casa, mas a visita torna-se um pesadelo quando o "tio" começa a tocá-las de maneira diferente. As obras são de extrema importância e utilidade, pois possui uma leveza e um toque lúdico para despertar no leitor mirim a atenção e prudência.

O motivo da escolha do tema partiu de uma discussão feita em sala de aula que despertou a vontade de aprofundamento no assunto, na qual se estudou o grande número de violência contra as crianças e adolescentes, principalmente dos números 
alarmantes no estado da Bahia. Ademais, percebeu-se a necessidade de levantar dados para que a pauta pudesse alcançar um maior número de leitores.

Sendo assim, o presente trabalho tem como problemática a seguinte questão: Como se apresenta alto índice de violência acometida a crianças e adolescentes no estado da Bahia, quais as características individuais que podem auxiliar a monitorar os casos. Explicitando à sociedade o resultado do abuso sexual e maus tratos na infância e adolescência. Traçando o perfil das vítimas de violência na Bahia em 2016, segundo dados disponíveis no DATASUS.

\section{MATERIAL E MÉTODOS}

Estudo descritivo e embasado em pesquisas bibliográficas, a qual abordou o tema violência infantil em crianças e adolescentes do estado da Bahia. Para escolha do tema e formação de ideias, foram considerados alguns dados do DATASUS, possibilitando a coleta de algumas informações e dando início ao desenvolvimento do artigo. Estudo epidemiológico para elaboração dos resultados, os dados no DATASUS serviram de fonte para a elaboração dos gráficos e desenvolvimento do resultado.

O primeiro contato com o DATASUS serviu para verificar o funcionamento da coleta de dados e para estudar quais dados seriam abordados. Após análise e seleção os dados necessários, os tipos de eixo abordados foram os eixos de sexo, raça, faixa etária, local de ocorrência, região e tipo de violência, sempre no filtro do estado. No DATASUS não foi possível fazer uma pesquisa restrita com relação à idade e ao estado porque o banco de dados não permite a aplicação de dois filtros, os critérios de inclusão foram dados do site referência de 2016 e os de exclusão foram artigos que mencionam violência que resultou em morte, artigos da Scielo que não abordava muito os temas, do ano de 2016 e assim foram desenvolvidos gráficos e discussão para ser apresentados no artigo. 


\section{RESULTADOS}

Analisando os dados colhidos no sistema do DATASUS, tendo como referência o ano de 2016, a pesquisa realizada apenas com o estado da Bahia e apresentando um total de 9.138 vítimas comparadas, torna-se possível notar os fatores relevantes de identificação da incidência das agressões. Destarte, levará a uma visão e análise crítica sob a situação e o cenário atual da face da violência. Diante disso, para um melhor nível de compreensão acerca dos resultados obtidos, fez-se necessário criar uma tabela e um gráfico com características sociodemográficas, genotípicas e tipos diferentes de violência. A coleta dos dados na base de dados referenciada resultou a tabela a seguir, sendo possível elucidar o problema em questão.

Tabela 1- Características sociodemográficas e genótipo de crianças e adolescentes vítimas de violências no estado da Bahia, 2016

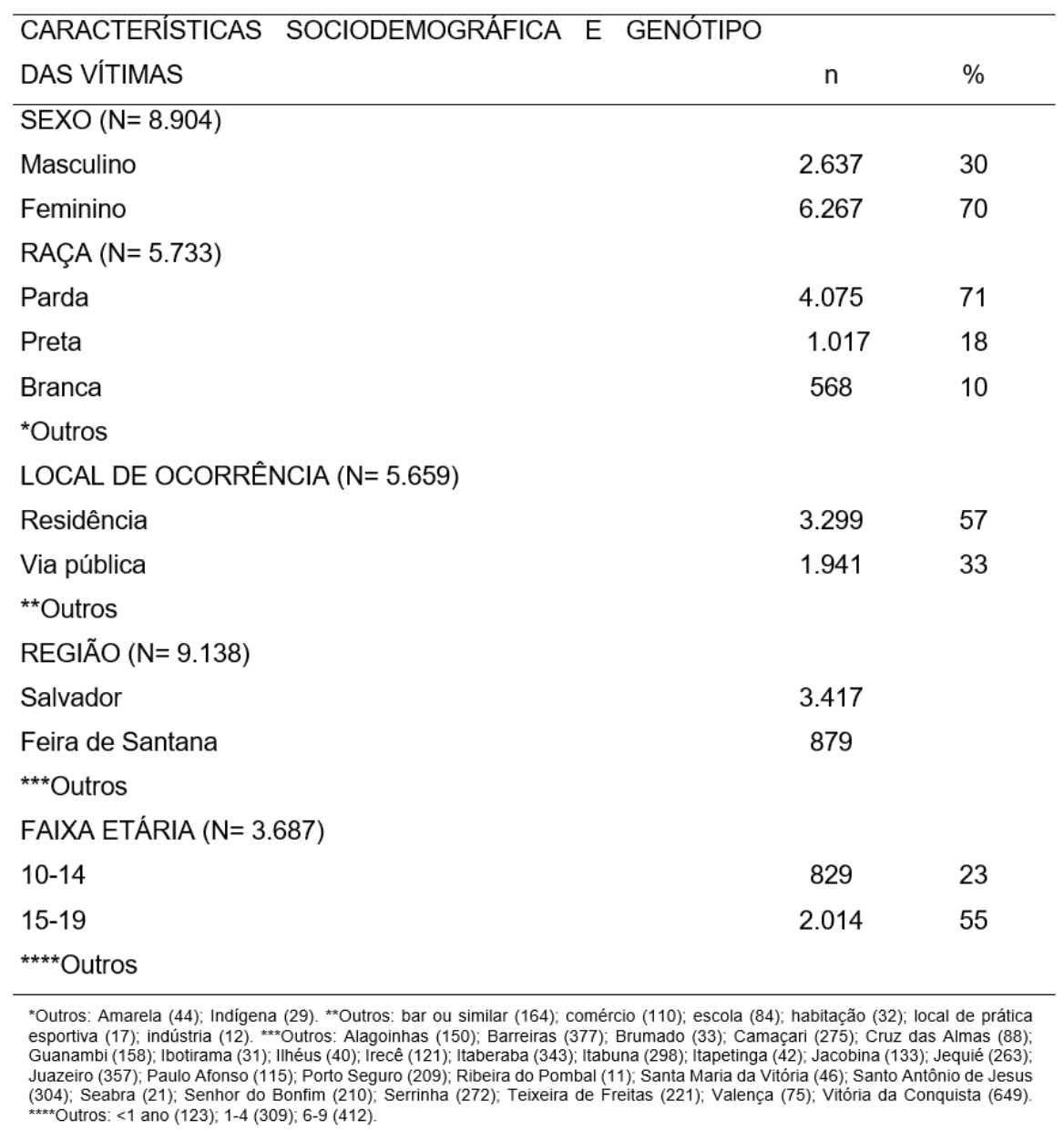


Notou-se que que o sexo mais atingido pela agressão é o feminino, correspondendo a $70 \%$ dos casos, fazendo então 6.267 vítimas, apenas dois casos não tiveram o sexo identificado. No que diz respeito ao estudo das raças em que há incidência de violência, levando em consideração que 3.405 dos casos vistos não se deixou explicito a etnia, nota-se que o maior grupo afetado é o de pessoas pardas (71\%).

Para que seja possível verificar a proporção do quem vem se tonando a violência infantil, há necessidade de maior atenção e incentivo a políticas públicas para proteção e acolhimento as crianças e adolescentes. Levantou-se também a classificação dos casos por faixa etária. É possível comprovar que o maior números de vítimas no estado baiano têm de 15 a 19 anos, correspondendo a $55 \%$ do total de casos vistos. As crianças menores de 1 ano que ainda requerem muitos cuidados, na maioria dos casos, são vistas com olhos mais afáveis, sendo os menos atingidos e correspondem a $3 \%$ dos casos, entre os padecedores 42 deles não tiveram a idade identificada e 5.409 eram adultos ou idosos.

Dentre os casos levantados 3.299 deles tiveram a agressão ocorrida dentro de suas residências, muitas vezes visto como um local caloroso e de descanso, mas que pode transformar-se em um pesadelo. As vias públicas também são cenários das atrocidades que um ser humano pode vir a fazer com seu próximo, sendo 1.941 casos presentes no levantamento em questão. Fazendo perceber que o estado necessita de mais segurança pública, que ações podem ser tomadas para resguardar a integridade dos baianos. As cidades mais perigosas, de acordo com a investigação feita em 2016, foram Salvador e em seguida Feira de Santana, em contrapartida a cidade menos perigosa foi Ribeira do Pombal. 
Gráfico 1- Tipos de violências que acometeram crianças e adolescentes no estado da Bahia, 2016.

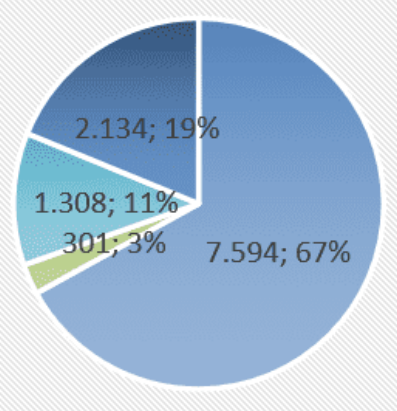

- Física

- Tortura

- Sexual

- Psico/moral

Fonte: Elaborado pelos autores

A forma de violência mais recorrente foi a física, podendo perceber também que a menor incidência é a tortura. Salientando que os resultados se referem aos casos denunciados, tendo assim uma ocorrência maior em cada segmento da violência.

\section{DISCUSSÃO}

Os resultados trazidos anteriormente não puderam ter maior grau de estreitamento, no que diz respeito a restringir a pesquisa apenas para o estado da Bahia, uma vez que o sistema do DataSus só permite a aplicação de dois filtros, impossibilitando a especificidade de algumas informações. Pelos dados postos, as cidades mais violentas do estado, Feira de Santana e Salvador, requerem uma maior atenção do poder público, visto que, a violência parece não alarmar o bastante a ponto de serem tomadas medidas de efetivo resultado ao invés de atuações paliativas.

Feira de Santana, segunda maior cidade do estado da Bahia, apresenta casos de violência infantil, sendo que a capital se encontra em primeiro lugar, mostra que $70 \%$ das vítimas da violência são do sexo feminino, de acordo com os resultados dessa pesquisa. Já a pesquisa de Silva e colaboradores em 2016, que foram vítimas examinadas por peritos no IML de Feira de Santana, onde 48,9\% foram do sexo masculino entre a idade de 16-18 anos, e o maior índice de lesão sendo na cabeça, é divergente dos dados apresentados nesse trabalho, porque foi abordado apenas a 
cidade de Feira de Santana, já os dados levantados nessa pesquisa foi de todo território Baiano.

De acordo com Nunes e colaboradores (2016) o lar se torna um local confortável para os agressores praticar a violência com as crianças e adolescentes, $75 \%$ dos artigos avaliados na pesquisa demonstram que as agressões foram feitas por membros da família da vítima, ou seja, muitos dos casos são ocorridos na própria casa da vítima. Em concordância com esse artigo, os dados são compatíveis, pois o maior índice de casos denunciados são que houveram a violência na residência, vale lembrar que os dados de Nunes e colaboradores são do Brasil, sendo que nos resultados dessa pesquisa, limitou-se ao estado da Bahia.

Rates e colaboradores (2016) em sua pesquisa realizada com crianças de todo território brasileiro, constatou que crianças entre 6 e 9 anos da cor parda são as maiores vítimas de violência no Brasil, com cerca de $52,6 \%$ dos casos. Nos resultados das pesquisas deste trabalho, as crianças e adolescentes da Bahia caracterizadas como pardas representam $71 \%$ dos casos de violência. Para Minayno (2001), crianças e adolescentes entre 7 e 13 anos sofrem mais violências no Brasil. Nessa pesquisa, observamos que os adolescentes entre 15 e 19 anos sofrem mais violência, com cerca de $55 \%$ dos casos

Segundo a pesquisa de Barreto e colaboradores (2018) a violência física tem o maior índice no estado da Bahia, com cerca de $47,6 \%$ e a segunda maior violência é a sexual. Semelhante às pesquisas de Barreto, a maior violência ocorrida na Bahia é a física, mas o segundo maior índice de violência nesse artigo foi a violência psicológica e moral, com $19 \%$ dos casos.

Coincidiu que, nos dados de Barreto e colaboradores (2018) a maior cidade do estado da Bahia com violência infantil é a capital, entre os anos de 2008 e 2014 no estado. Nesta pesquisa, Salvador também é a maior cidade a ter casos denunciados no território baiano no ano de 2016, com cerca de 3.417 casos registrados. 
A plataforma de acolhimento das denúncias Disque 100, recebem casos de exploração sexual, aliciamento de menores, pornografia infantil, turismo sexual, entre outros. O Conselho Tutelar, órgão previsto no Estatuto da Criança e do Adolescente, serve para reforçar a garantia dos direitos das crianças e adolescentes. Atende ao público infanto juvenil, pais, responsáveis legais e sempre busca a proteção dos menores. Encaminha os casos ao Ministério Público e poder judiciário, tendo que tomar providencias para ter a certeza de que as medidas decidas serão tomadas.

\section{CONCLUSÃO}

O presente artigo, visando abordar e transparecer o perfil de crianças e adolescentes vitimas de violência no Estado da Bahia, bem como os percentuais finais tendo como base os números extraídos do DATASUS, mostrou que o sexo mais atingido é o feminino, em relação ao percentual de raça a mais acometida é a parda. Tornou possível designar um norte para que se possa começar a tratar do problema onde ímpeto está mais avançado. É notável que são necessárias medidas mais efetivas na área de saúde e no âmbito jurídico.

É claro que a violência, em qualquer que seja a fase da vida, além de sequelas físicas acarretam também os problemas psicológicos que são levados para toda a vida, interferindo inclusive nas relações interpessoais. Estrago maior é feito quando ocorre na infância, tendo em vista que as crianças e adolescentes estão em processo de desenvolvimento.

De acordo o DATASUS, foram identificados 8.905 casos de violências contra crianças e adolescentes de 0 a 19 anos. O local mais violento nos casos pesquisados é a residência da vítima, sendo as meninas o maior número de agressões e no que diz respeito a raça, a cor parda prevaleceu. Quanto a idade os indivíduos mais violentados tinham entre 15 e 19 anos, totalizando 1999 casos. A cidade mais violenta para essa faixa etária foi Salvador seguida de Feira de Santana.

Para a população denunciar casos de violência contra crianças e adolescentes o Ministério Público disponibiliza o disk 100, a ligação é gratuita e abrange todo o 
território nacional. Em relação aos tipos de violência, a física ficou em primeiro lugar, seguida da psicológica/moral, terceiro lugar ficou a violência sexual e em quarto a tortura. Mas ressalta-se que tomas as medidas tomas ainda não são suficientes, pois o assunto requer sempre mais atenção.

\section{REFERÊNCIAS}

ARCARI, Caroline. Pipo e Fifi. Disponível em: <https://www.pipoefifi.com.br/> Acesso em 04 de maio de 2019.

AQUINO, Carol. Bahia: violação de direitos de crianças e adolescentes

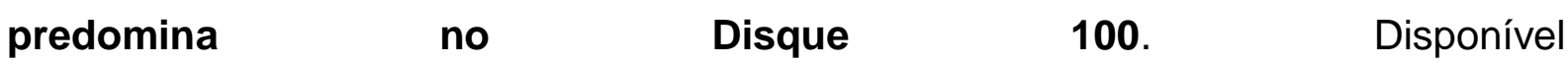
em:<https://www.correio24horas.com.br/noticia/nid/bahia-violacao-de-direitos-decriancas-e-adolescentes-predomina-no-disque-100/>. Acesso em 30 de abril de 2019.

BAHIA, Defensoria pública. Bahia é campeã em denúncias de violência sexual infanto-juvenil. Disponível em: <https://dpba.jusbrasil.com.br/noticias/2695953/bahia-e-campea-em-denuncias-de-violenciasexual-infanto-juvenil>. Acesso em 30 de abril de 2019.

BARRETO, C.S.L.S; JUNIOR, D.F.M; ARAUJO, R.P. C. A violência praticada contra a criança no estado da bahia: autoria e meios de agressão. Ciências médicas e biológicas v:15, n.1, p.85-86, 2016.

BARRETO, C.S L.A; ARAUJO, R.P.C; JUNIOR, D.F.M; FILHO, R.C.B; COSTA, M.C.O. Perfil da violência que vítima crianças no estado da Bahia, segundo registros do sistema de gerenciamento estatístico (SGE) da secretaria de segurança pública, Saúde coletiva da UEFS v:8, n:5-15, p. 10-11, 2018.

\section{CABETTE, E. L. S. Artigos 136 do Código Penal e 232 do Estatuto da Criança e} do Adolescente - conflito aparente de normas. Disponível em: <https://eduardocabette.jusbrasil.com.br/artigos/121937297/artigos-136-do-codigopenal-e-232-do-estatuto-da-crianca-e-do-adolescente-conflito-aparente-de-normas>. Acesso em 30 de abril de 2019. 
CHILDHOOD. Quem somos. Disponível em: <https://www.childhood.org.br/quemsomos>. Acesso em 04 de maio de 2019.

DATASUS. http://tabnet.datasus.gov.br/cgi/deftohtm.exe?sinannet/cnv/violeba.def>. Acesso em 29 de abril de 2019.

EQUIPE DA OUVIDORIA NACIONAL DOS DIREITOS HUMANOS. Balanço anual Ouvidoria. Disponível em: <https://www.mdh.gov.br/informacao-aocidadao/ouvidoria/dados-disque-100/relatorio-balanco-digital.pdf $\geq$.Acessado em 22 de abril de 2019

FUNDAÇÃO TELEFÔNICA. Atribuições do Conselho Tutelar. Disponível em: $<$ http://fundacaotelefonica.org.br/promenino/trabalhoinfantil/conselhotutelar/atribuico es-do-conselho-tutelar/>. Acesso em 01 de maio de 2019.

MINAYO, M.C.S. Violência contra crianças e adolescentes: questão social, questão de saúde, Brasileira de saúde materno infantil, v.1, n.2, 2001.

NÃO BATA, EDUQUE. Quem somos. Disponível em: <http://naobataeduque.org.br/quem-somos/> Acesso em: 04 de junho de 2019.

NUNES, A.J; SALES, M.C.V. Violência contra crianças no cenário brasileiro, Ciência e saúde coletiva, 2016.

OLIVEIRA, Ana Clara. "Não me toca, seu boboca!" autora do livro fala sobre abuso infantil. Disponível em: <https://leiturinha.com.br/blog/nao-me-toca-seuboboca-autora-do-livro-fala-sobre-abuso-infantil/> Acesso em 04 de maio de 2019.

RATES, S.M.M; MELO, E. M; MASCARENHAS, M.D.M; MALTA, D.C. Violência infantil uma análise das notificações compulsórios 2011, Ciência e saúde coletiva, v. 1, n. 1, p. 660, 2016. 
SILVA, M.L.C.A. Lesões corporais em crianças e adolescentes vítimas de violência: casos periciados no IML de Feira de santana- Bahia, Biblioteca digital de teses e dissertações UEFS, 2016.

VIGNE, Julia. Por dia, seis crianças ou adolescentes sofrem violência sexual na Bahia. Disponível em: <https://www.correio24horas.com.br/noticia/nid/por-dia-seiscriancas-ou-adolescentes-sofrem-violencia-sexual-na-bahia/>. Acesso em 30 de abril de 2019.

WIKIPEDIA. Estatuto da Criança e do Adolescente. Disponível em:<https://pt.wikipedia.org/wiki/Estatuto_da_Crian\%C3\%A7a_e_do_Adolescente $>A$ cesso em: 01 de maio de 2019.

WIKIPEDIA. Violência. Disponível em:<https://pt.wikipedia.org/wiki/Viol\%C3\%AAncia>. Acesso em 30 de abril de 2019.

Enviado: Janeiro, 2020.

Aprovado: Junho, 2020. 